\title{
Assisted Reproductive Technology and Congenital Malformations
}

\author{
Johanna A. Reed and Alastair G. Sutcliffe \\ University College London \\ United Kingdom
}

\section{Introduction}

Assisted reproductive technology (ART) encompasses all medical intervention used to assist people becoming parents, mainly but not solely as a result of infertility. In vitro fertilisation (IVF) is the cornerstone of ART. It involves stimulating the ovaries, retrieving and culturing oocytes which are then inseminated with capacitated spermatozoa. The embryo is cultured and transferred into the uterus. The first successful IVF pregnancy came to term in 1978. Since then numbers have rapidly increased and it now accounts for nearly $2 \%$ of births in the UK and more than 4 million worldwide (Human Fertilisation and Embryology Authority, 2011; ICMART, 2008).

There has always been concern about the possibility of an increased rate of congenital malformations in children conceived using ART. Analysis of early longitudinal data from Australia showed a higher rate of transposition of the great arteries and spina bifida in individuals conceived by IVF than expected (Lancaster, 1987). In IVF, sperm and eggs are removed from their normal environment and subject to altered hormones, handling and culture media. Newer techniques such as Intracytoplasmic sperm injection (ICSI) and preimplantation genetic diagnosis (PGD) are even more invasive, potentially leaving the developing embryo at greater risk of malformation. Major malformations are usually defined as those which generally cause functional impairment, other conditions are considered to be minor anomalies (Holmes, 1976).

Studying ART outcomes has proved difficult. Initial studies were small and there was a confounding high incidence of multiple births. Methodological pitfalls included difficulty finding adequate control groups as the ART population differs from the general population. The underlying cause of infertility might itself lead to pregnancy loss and congenital malformation and surveillance is often more rigorous following ART pregnancies (Simpson, 1996).

As more babies are born as a result of these techniques, there is more data available regarding the outcomes, and increasing evidence that there is a slightly higher risk of congenital malformations than following spontaneous conception. This chapter begins with an overview of ART and then moves on to discuss associated malformations and potential mechanisms. It was produced following a Medline search using the MeSH terms 'fertilisation in vitro' AND 'congenital malformation'. References from articles selected were reviewed to find additional articles. 


\section{Assisted reproductive technology}

The term assisted reproductive technology (ART) covers a range of techniques to enable people to have children who wouldn't otherwise be able to. It can be used to assist fertilisation in vivo with ovulation induction, intra uterine insemination and gamete intrafallopian transfer (GIFT). When in vivo fertilisation is not possible in-vitro fertilisation (IVF) is described above.

Intracytoplasmic sperm injection (ICSI) was initially used where sperm are unable to fertilise the egg. A single sperm is selected based on morphological characteristics and injected into the oocyte cytoplasm. It was first used in 1992 (Palermo et al., 1992) and its high success rate has led it to be used in many centres for all cause infertility. If sperm can not be produced without medical intervention it can be collected directly from the epididymis by percutaneous epididymal sperm aspiration (PESA) or from the testicles, by testicular sperm aspiration (TESA). It is also possible to remove tiny quantities of testicular tissue from which sperm can be extracted using testicular sperm extraction (TESE). As only small numbers of sperm are produced by these methods, ICSI is then used to achieve fertilisation. Âă

Preimplantation genetic screening or diagnosis (PGS/PGD) is used in families known to have a genetic disease or with previous recurrent miscarriages. It is used to select either embryos without disease or âĂŸsaviour siblingsâĂŹ where HLA matched cells could be used as treatment for an already affected individual (Rubio, 2010). Embryos are produced by IVF or ICSI and then one or two cells are taken from the embryo by a trained embryologist at day two or three and tested for the features required. Acceptable embryos are transferred to the uterus to allow them to develop and suitable remaining unaffected embryos can be cryopreserved for later use. Embryos which are affected by the condition are allowed to perish.

Eggs, ovarian tissue, sperm and embryos can be cryopreserved for use in the future. Embryos are usually from IVF cycles, gametes are stored to preserve fertility for example while undergoing treatment for cancer. With an increase in single embryo transfer, more embryos are being frozen and this can be done at several stages with potential for differing outcomes. Egg cryopreservation is the most recent possibility as it has been difficult to develop techniques to prevent eggs bursting.

\section{Adverse perinatal outcomes}

Initial longitudinal studies of IVF in England (MRC Working Party on Children Conceived by In Vitro Fertilisation, 1990) and Australia (Australian in vitro fertilisation collaborative group, 1985) showed poor outcomes for IVF infants with significant low birth weight and prematurity. These risks have subsequently been confirmed by multiple studies and systematic reviews (Hansen et al., 2005; 2002; Helmerhorst et al., 2004; Jackson et al., 2004; Schieve et al., 2007; 2002).

The most well documented risk of ART is multiple births. Assisted conception accounts for $1.7 \%$ of all births but $21 \%$ of multiple births in the UK (Human Fertilisation and Embryology Authority, 2011). Higher order births are more likely to be born preterm, have a lower birth weight and have congenital malformations. Single embryo transfer is now promoted which has reduced these complications. Despite this ART children still have a higher perinatal morbidity and mortality than matched controls (Al-Fifi et al., 2009; Helmerhorst et al., 2004). A systematic review found that for singletons the relative risk of a very preterm birth $(<32$ weeks) was 3.27 (95\% CI 2.03 -5.28) after assisted conception (Helmerhorst et al., 2004). 


\section{Congenital malformations}

A large number of studies have been conducted looking at malformations in ART conceived children. Couples using ART differ from the general population in several ways and results have been particularly complicated by difficulty finding adequate control groups. Typically they are older, have a higher socioeconomic status and are infertile. The underlying cause of infertility might itself lead to malformation and it is difficult to find appropriate infertile controls who have spontaneously conceived. It may be that couples are less likely to terminate pregnancies conceived by IVF thus increasing the rate of children born with congenital malformations. In early studies ART offspring were rigorously examined and malformation rates then compared to the general population who may have only undergone superficial examination and malformations may not have been recorded appropriately. Many studies only examined children for abnormalities at birth when fewer congenital anomalies can be identified compared to at 6 months of age. Birth defects should be assessed without knowledge of conception status but it has been shown that paediatricians are relatively good at determining this from other cues (Ludwig, Katalinic, Entenmann, Thyen, Sutcliffe, Diedrich \& Ludwig, 2009). There are few studies looking at ART outcomes in people using the techniques for reasons other than infertility.

It is possible that ART may predispose to only certain types of malformations. The initial Australian study suggested a link with cardiac and neural tube defects (Lancaster, 1987). An early study of all infants born in Sweden after IVF, 1982âĂŞ1997 (n = 9111) found a 3-fold excess risk of neural tube defects, alimentary atresia and omphalocele (Ericson \& Källén, 2001). It found an increased risk for hypospadias after ICSI but not after standard IVF. In a follow up study this group continued to find an increased risk of neural tube defects, choanal atresia and alimentary tract atresia in this population (?). Further work in Australia found a specific association between ART and 'blastogenesis birth defects' arising in the first 4 weeks of pregnancy such as abdominal wall defects, vertebral segmentation defects, tracheoesophageal fistula, diaphragmatic defects, neural tube defects, anal atresia and renal agenesis. They were present in 1 in 160 ART pregnancies compared with 1 in 400 controls (Halliday et al., 2010).

A recent study from Paris found cases of congenital heart disease were more likely to have been conceived using ART (Tararbit et al., 2011). ART was specifically associated with significant increases in the odds of malformations of the outflow tracts and ventriculoarterial connections (adjusted OR 1.7, 95\% CI 1.2âĂŞ2.4) and of cardiac neural crest defects and double outlet right ventricle (adjusted OR 1.7, 95\% CI 1.1âĂŞ2.7) (Tararbit et al., 2011). A retrospective cohort study again found a higher rate of cardiovascular malformations in infants conceived by ART than controls (Wen et al., 2010). An American study of infants with birth defects found more infants had been conceived by ART and a specific association with septal heart defects (Reefhuis et al., 2009). Fetal echocardiography did not find an increase of congenital heart defects above the general population but it did find higher rates in twin pregnancies compared to singletons which may contribute to earlier findings (Bahtiyar et al., 2010).

Several studies have found an increased rate of cerebral palsy in children born following IVF (Hvidtjørn et al., 2010; 2006; Lidegaard et al., 2005; Zhu et al., 2010). In some cases this has been accounted for by the high rate of multiple births and preterm delivery (Hvidtjørn et al., 2010; 2006). Some have found the risk remains increased when accounting for these confounders (Lidegaard et al., 2005; Zhu et al., 2010; ?).

Looking at malformations overall Rimm et al. performed a meta-analysis of 19 controlled studies comparing major malformation rates in IVF and ICSI children with spontaneously 
conceived children (Rimm et al., 2004). They found an odds ratio for major malformations of 1.29 (95\%CI 1.01-1.67) in children conceived by IVF/ICSI. There was no significant difference in malformation rates in individuals conceived by IVF compared to ICSI. There was a lot of variation in major malformation rates between studies. The odds ratio for malformations was higher in singletons compared to multiple births, probably because of the increase in monozygotic twins with a higher rate of malformations after spontaneous conception. There were many problems identified with the studies used in this meta- analysis. Most used inappropriate groups of healthy controls which often did not control for the older age and fertility problems of parents using ART. There was no distinguishing if cryopreservation had been used.

Overall, meta-analysis has shown a 40-50\% increased rate of major malformations following ART (Hansen et al., 2005; Lie et al., 2005; Rimm et al., 2004). A recent update (Rimm et al., 2011) included an augmented calculation of the contribution of infertility (Zhu et al., 2006). This found ART does not increase the risk of major malformations as much as previously reported when subfertile couples are used as controls suggesting a proportion of the increased risk of congenital malformations following IVF is due to the underlying subfertility rather than ART per se.

\section{Mechanisms leading to congenital malformations in ART children}

\subsection{Point mutations}

In very rare cases a mutation can be found which has shown variable expression, causing infertility in the parent and a more apparent congenital malformation in the offspring.

\subsubsection{IHH and SOX2 mutations}

A mother with idiopathic hypogonadotrophic hypogonadism had given birth to two children following ovulation induction. One had anopthalmia and one had unilateral micropthalmia (Stark et al., 2011). All three were subsequently found to be carriers of a SOX2 mutation. Studies appeared to show the mother carried a lower level of DNA with this mutation but they were unable to determine if she was a mosaic.

\subsubsection{Cystic fibrosis}

Previous studies have shown CFTR mutations in a significant proportions in azoospermic $(31 \%)$ and oligospermic (22\%) men (Gallati et al., 2009). If the mother is also heterozygous for a CFTR mutation the offspring may have more manifestations of cystic fibrosis.

\subsection{Chromosomal abnormalities}

Chromosomal abnormalities are an uncommon cause of malformations following ART. About $4.6 \%$ of infertile men with with oligospermia and $13.7 \%$ with aspermia and have a coexistent chromosome abnormality which is most frequently a deletion in the long arm of the $\mathrm{Y}$ chromosome (Foresta \& Ferlin, 2001; Vicdan et al., 2004). A recent study found 4.3\% (5/115) azoospermic men had a karyotype abnormality, $80 \%$ of these were Kleinfelters syndrome (Koşar et al., 2010). Most centres now perform a karyotype as part of a basic infertility screen. 


\subsubsection{Ring $Y$}

A case has been reported of an infant conceived by ICSI with ambiguous genitalia (Spinner et al., 2008). The father had presented with infertility and oligospermia. The child's karyotype was $47, \mathrm{XXr}(\mathrm{Y})[10] / 46, \mathrm{XX}[40]$. The ring $\mathrm{Y}$ chromosome was inherited from the father. A simillar case from an oligospermic father following ICSI has been reported previously, in a child with a 45,X/46,Xr(Y) mosaicism (Bofinger et al., 1999).

\subsubsection{Aneuploidy}

Cases have been reported of an unusual karyotype in association with trisomy 21 in individuals conceived by IVF with embryo cryopreservation. One report described a mosaic where one cell line contained an additional copy of chromosome 21 as part of a Robertsonian translocation and the other cell line contained a ring chromosome 21 (Guran et al., 2010).

An evaluation of products of conception following miscarriage in ART pregnancies or spontaneous conception in subfertile couples showed an abnormal karyotype in $63.2 \%$ cases after ART and in $71.5 \%$ after natural conception in subfertile couples.41 Overall $60 \%$ of such abortuses would be expected to have an abnormal karyotype. Only 10 ICSI-TESE cases were analysed, and there was a discrepancy between chromosome abnormalities detected in this group $(80 \%)$ compared to ICSI $(61.5 \%)$. 50\% showed triploid/tetraploid karyotypes, when in the other groups polyploidy did not exceed $17.5 \%$. Although numbers are very small authors hypothesize that the use of immature testicular spermatozoa confers a higher risk of cytogenetically abnormal conceptions (Bettio et al., 2008).

\subsection{Epigenetic abnormalities}

Imprinted genes are those where only one allele is normally expressed, according to the parent of origin (Amor \& Halliday, 2008). About 1\% of human genes are thought to be imprinted, typically paternally expressed genes promote growth whereas maternally expressed genes suppress growth. The signal for this origin specific expression is an epigenetic change in the form of methylation and histone modification, changing the structure of the DNA rather than the sequence. With each generation the imprinted signal is erased and re-establised during gametogenesis.

Several mechanisms can lead to errors of imprinting, some of which cause recognised syndromes. There may be a mutation in one allele of an imprinted gene which prevents its expression or a larger deletion encompasing a whole gene or its imprinting control centre. A child can inherit two copies of a chromosome from one parent, uniparental disomy. An alternative mechanism is an epigenetic abnormality, for example affecting methylation. For each of the recognised imprinting syndromes the rates with which each mechanism accounts for cases differs.

There have been reports of unexpectedly raised rates of imprinting disorders in children born after assisted conception. Analysis indicates that imprinting defects in these individuals are largely due to epigenetic defects, specifically aberrant DNA methylation (Bahtiyar et al., 2010; Odom \& Segars, 2010). It is hypothesised that the erasure and reestablishment of the imprinting signal may be disrupted by some forms of ART. The demands placed on the embryo by ART may induce adaptations in foetal epigenetic patterns eventually leading to such imprinting disorders. Indeed, altered epigenetic patterns have been found in assisted conception embryos, cord blood and placenta (Turan et al., 2010). 
Loss or gain of the epigenetic signal can occur on either the maternal or paternal allele but in most reported cases affecting ART children the problem is hypomethylation on the maternal allele (Amor \& Halliday, 2008). There is no evidence other mechanisms such as large deletions or duplications giving an imbalance of the imprinted genes occur at higher incidence due to ART. This is interesting as ART mothers are typically older so an increased incidence of uniparental disomy could be expected.

It is difficult to know whether the abnormal methylation causing these imprinting defects is as a result of one of the many processes encompassed by ART or associated with subfertility. Studies of superovulated oocytes from infertile women have shown altered methylation (Sato et al., 2007).

Genomic imprinting may be less complete when immature gametes are used (Tesarik \& Mendoza, 1996). There is currently no evidence of increased numbers of individuals with imprinting defects conceived by PESA and TESA but numbers are too small to draw any firm conclusions and further study is required.

Two particular imprinting syndromes which seem to be at higher rates following ART are Angelman syndrome and Beckwith Weidemann syndrome (BWS).

BWS is an overgrowth syndrome where individuals are affected by neonatal hypoglycaemia, macroglossia, macrosomia and midline abdominal wall defects (omphalocele, umbilical hernia, diastasis recti). It is caused by uniparental disomy or imprinting defect affecting chromosome 11p15 (Shuman et al., 2005). Several studies have found increased rates of BWS in children born following ART (Halliday et al., 2004; Maher et al., 2003). Studies in the UK, USA and France have found children with BWS were more likely to have been conceived by ART (Chang et al., 2005; Gicquel et al., 2003; Maher et al., 2003). These cases were largely caused by imprinting defects. One case report describes a family where two children have been born with BWS, one following IVF and one spontaneously conceived (following years of infertility treatment) suggesting in this case the IVF was not the cause (Strawn et al., 2010). Interestingly in animals conceived by IVF or nuclear transfer a large offspring syndrome has been described which shares similarities with BWS (Gicquel et al., 2003).

Angelman syndrome affects ấij1 in 16000 children and is characterized by severe intellectual disability, speech impairment, a happy demeanour, ataxia, seizures and microcephaly. It is caused by abnormalities affecting the maternal copy of chromosome 15q11-13. Overall $5 \%$ of cases are associated with an imprinting defect. Early case reports described cases of Angelman syndrome conceived using ICSI with AS secondary to loss of methylation. A higher proportion of cases of AS in children born using ART seem to be as a result of methylation defects. Interestingly a German cohort found an excess of AS cases again with methylation defects in children spontaneously conceived by subfertile couples (Lidegaard et al., 2005).

Two case reports have described hypomethylation of the paternally derived H19/IGF2 locus in infants with Russell-Silver syndrome conceived by ICSI (Chopra et al., 2010; Douzgou et al., 2008). Several other children born following ART with this syndrome have also been described. Beyond the classically recognised imprinting syndromes, decreased methylation has been found in spontaneously conceived individuals with neural tube defects (Wang et al. 2010). Further work is needed to see if this is consistent with the explanation for the possible increase in ART.

Many of the imprinting syndromes are very rare. Even if ART increases the risk of these disorders by two or three times it will still be very difficult to detect this increased risk. The 
Danish National IVF cohort study found no cases of imprinting disorders in the 6052 children born following IVF between 1995 and 2001 (Lidegaard et al., 2005).

\section{Association of malformations with different types of ART}

Most studies have found few differences in the malformation rates between different types of ART. It could be hypothesized that the more invasive techniques are likely to carry a higher risk of malformation but many techniques have not yet been used enough to show definitive results. It seems likely that techniques allowing in vivo fertilization (eg GIFT) are safer than those relying on in vitro fertilization. To support this no increase in malformations have been observed following ovarian stimulation (?).

An early study of 91 infants born following embryo cryopreservation found a relative risk of a major malformation of 1.4 including cases of Beckwith Weidemann syndrome and Downs syndrome (Sutcliffe et al., 1995). More recent work has shown an increase in aneuploidys in embryos following cryopreservation (Guran et al., 2010). Other work has shown no increase in malformations when using frozen embryos over fresh ( $\mathrm{Li}$ et al., 2010). A systematic review found comparable results for IVF using fresh or frozen embryos (Wennerholm et al., 2009).

Some of the most definitive work shows that children conceived by ART are at a higher risk of reproductive tract anomalies, particularly hypospadius in boys conceived by ICSI (Funke et al., 2010; Klln et al., 2005b; ?). Prematurity, low birthweight, and multiple gestation, are indirect risk factors for developing male genital malformations but in infants with normal birthweight or from singleton pregnancies, ICSI is a specific risk factor for hypospadias.(Funke et al., 2010) More boys conceived by ICSI were also found to have undescended testes requiring surgery (Ludwig, Katalinic, Thyen, Sutcliffe, Diedrich \& Ludwig, 2009). In ICSI the sperm has been unable to fertilise the egg and is therefore in some way abnormal. It is possible that men who are only able to have children by ICSI, in some cases pass on this defect to their sons. In ICSI using epididimal or testicular sperm (MESA and TESA) a systematic review (Woldringh et al., 2010) found there is not enough data to reliably say if this affects the rate of congenital malformations in subsequent offspring although one study had found a higher rate of polyploidy in abortuses (Mateu et al., 2010).

Early reports from cases series of individuals conceived following preimplantation genetic diagnosis show no risk of malformations over ICSI but there was an increased perinatal death rate (Liebaers et al., 2010).

\section{Conclusions}

There is mounting evidence that infants conceived by these methods are at slightly higher risk of congenital abnormalities overall with particularly compelling evidence for imprinting syndromes and urogenital malformations. Some of the increased risk of congenital malformations following ART appears to be the effect of subfertility rather than ART per se.

This conclusion is echoed by a recent ESHRE position statement which states "Children from couples who get pregnant after assisted reproduction techniques, like IVF/ICSI, have a $40-50 \%$ increased risk for a birth defect. A similar increased risk has been reported for subfertile couples who get pregnant spontaneously after a prolonged time period. This increased risk seems thus mainly be due to parental characteristics from the infertility status and not to the treatment given." 
It is still early days. Louise Brown, the first person born by IVF is now in her 30s and has given birth to a spontaneously conceived child. The oldest person born by ICSI is only 20 . There are case reports of people born following ART with a range of syndromes for example Goldenhar syndrome and Rubinstein-Taybi syndrome conceived by ICSI (Balci et al., 2008). It is too early to say if this is a chance finding or a genuine association. As the number of people born following ART increases and they move through their lives It is important they continue to be monitored particularly as new techniques are developed so people using these techniques, which overall are relatively safe, can be given an accurate picture of the risks they face and future children can be monitored appropriately.

\section{References}

Al-Fifi, S., Al-Binali, A., Al-Shahrani, M., Shafiq, H., Bahar, M., Almushait, M., Sobandi, L. \& Eskandar, M. (2009). Congenital anomalies and other perinatal outcomes in ICSI vs. naturally conceived pregnancies: a comparative study., Journal of assisted reproduction and genetics $26(7): 377-81$.

Amor, D. J. \& Halliday, J. (2008). A review of known imprinting syndromes and their association with assisted reproduction technologies., Human reproduction (Oxford, England) 23(12): 2826-34.

Australian in vitro fertilisation collaborative group (1985). High incidence of preterm births and early losses in pregnancy after in vitro fertilisation., British medical journal (Clinical research ed.) 291(6503): 1160-3.

Bahtiyar, M. O., Campbell, K., Dulay, A. T., Kontic-Vucinic, O., Weeks, B. P., Friedman, A. H. \& Copel, J. A. (2010). Is the rate of congenital heart defects detected by fetal echocardiography among pregnancies conceived by in vitro fertilization really increased?: a case-historical control study., Journal of ultrasound in medicine : official journal of the American Institute of Ultrasound in Medicine 29(6): 917-22.

Balci, S., Engiz, O., Alikasifoglu, M., Esinler, I. \& Sinan Beksac, M. (2008). Association of assisted reproductive technology with twinning and congenital anomalies., Indian journal of pediatrics 75(6): 638-40.

Bettio, D., Venci, A. \& Levi Setti, P. E. (2008). Chromosomal abnormalities in miscarriages after different assisted reproduction procedures., Placenta 29 Suppl B: 126-8.

Bofinger, M., NEEDHAM, D., Saldana, L., Sosnowski, J. \& Blough, R. (1999). 45, X/46, x, r (y) karyotype transmitted by father to son after intracytoplasmic sperm injection for oligospermia: a case report, Journal of reproductive medicine 44(7): 645-648.

Chang, A. S., Moley, K. H., Wangler, M., Feinberg, A. P. \& Debaun, M. R. (2005). Association between Beckwith-Wiedemann syndrome and assisted reproductive technology: a case series of 19 patients., Fertility and sterility 83(2): 349-54.

Chopra, M., Amor, D. J., Sutton, L., Algar, E. \& Mowat, D. (2010). Russell-Silver syndrome due to paternal H19/IGF2 hypomethylation in a patient conceived using intracytoplasmic sperm injection., Reproductive biomedicine online 20(6): 843-7.

Douzgou, S., Mingarelli, R., Tarani, L., De Crescenzo, A. \& Riccio, A. (2008). Silver-Russell syndrome following in vitro fertilization., Pediatric and developmental pathology: the official journal of the Society for Pediatric Pathology and the Paediatric Pathology Society 11(4): 329-31.

Ericson, A. \& Källén, B. (2001). Congenital malformations in infants born after IVF: a population-based study., Human reproduction (Oxford, England) 16(3): 504-9.

Foresta, C. \& Ferlin, A. (2001). Offspring conceived by intracytoplasmic sperm injection, Lancet 358(9289): 1270. 
Funke, S., Flach, E., Kiss, I., Sándor, J., Vida, G., Bódis, J. \& Ertl, T. (2010). Male reproductive tract abnormalities: more common after assisted reproduction?, Early human development 86(9): 547-50.

Gallati, S., Hess, S., Galié-Wunder, D., Berger-Menz, E. \& Böhlen, D. (2009). Cystic fibrosis transmembrane conductance regulator mutations in azoospermic and oligospermic men and their partners., Reproductive biomedicine online 19(5): 685-94.

Gicquel, C., Gaston, V., Mandelbaum, J., Siffroi, J., Flahault, A. \& Le Bouc, Y. (2003). In vitro fertilization may increase the risk of Beckwith-Wiedemann syndrome related to the abnormal imprinting of the kcnq1ot gene, American journal of human genetics 72(5): 1338.

Guran, S., Rosti, R. O., Sarici, S. m., Torun, D., Kozan, S. \& Bahçe, M. (2010). Rare chromosomal complement of trisomy 21 in a boy conceived only by IVF., Reproductive biomedicine online 21(5): 721-2; author reply 723.

Halliday, J. L., Ukoumunne, O. C., Baker, H. W. G., Breheny, S., Jaques, A. M., Garrett, C., Healy, D. \& Amor, D. (2010). Increased risk of blastogenesis birth defects, arising in the first 4 weeks of pregnancy, after assisted reproductive technologies., Human reproduction (Oxford, England) 25(1): 59-65.

Halliday, J., Oke, K., Breheny, S., Algar, E. \& J Amor, D. (2004). Beckwith-Wiedemann syndrome and IVF: a case-control study., American journal of human genetics 75(3): 526-8.

Hansen, M., Bower, C., Milne, E., de Klerk, N. \& Kurinczuk, J. J. (2005). Assisted reproductive technologies and the risk of birth defects-a systematic review., Human reproduction (Oxford, England) 20(2): 328-38.

Hansen, M., Kurinczuk, J. J., Bower, C. \& Webb, S. (2002). The risk of major birth defects after intracytoplasmic sperm injection and in vitro fertilization., The New England journal of medicine 346(10): 725-30.

Helmerhorst, F., Perquin, D., Donker, D. \& Keirse, M. (2004). Perinatal outcome of singletons and twins after assisted conception: a systematic review of controlled studies, BMJ 328(7434): 261.

Holmes, L. B. (1976). Current concepts in genetics. congenital malformations., The New England journal of medicine 295(4): 204-7.

Human Fertilisation and Embryology Authority (2011). Fertility facts and figures, Human reproduction pp. 21-4.

Hvidtjørn, D., Grove, J., Schendel, D., Svaerke, C., Schieve, L., Uldall, P., Ernst, E., Jacobsson, B. \& Thorsen, P. (2010). Multiplicity and early gestational age contribute to an increased risk of cerebral palsy from assisted conception: a population-based cohort study, Human reproduction (Oxford, England) 25(8): 2115-23.

Hvidtjørn, D., Grove, J., Schendel, D., Vaeth, M., Ernst, E., Nielsen, L. \& Thorsen, P. (2006). Cerebral palsy among children born after in vitro fertilization: the role of preterm delivery-a population-based, cohort study, Pediatrics 118(2): 475-82.

ICMART (2008). Presentation of preliminary data for 2004, Human reproduction (Oxford, England) .

Jackson, R., Gibson, K., Wu, Y. \& Croughan, M. (2004). Perinatal outcomes in singletons following in vitro fertilization: a meta-analysis, Obstetrics \& Gynecology 103(3): 551.

Källén, B., Finnström, O., Nygren, K. \& Olausson, P. (2005a). In vitro fertilization (IVF) in Sweden: infant outcome after different IVF fertilization methods, Fertility and sterility 84(3): 611-7. 
Klln, B., Finnstrm, O., Nygren, K. \& Olausson, P. (2005b). In vitro fertilization (IVF) in Sweden: risk for congenital malformations after different IVF methods, Birth Defects Research Part A: Clinical and Molecular Teratology 73(3): 162-169.

Källén, B., Olausson, P. \& Nygren, K. (2002). Neonatal outcome in pregnancies from ovarian stimulation, Obstetrics \& Gynecology 100(3): 414.

Koşar, P. A., Ozçelik, N. \& Koşar, A. (2010). Cytogenetic abnormalities detected in patients with non-obstructive azoospermia and severe oligozoospermia., Journal of assisted reproduction and genetics $27(1): 17-21$.

Lancaster, P. A. (1987). Congenital malformations after in-vitro fertilisation., Lancet 2(8572): 1392-3.

Li, H., Qiao, J., Chi, H., Chen, X., Liu, P. \& Ma, C. (2010). Comparison of the major malformation rate of children conceived from cryopreserved embryos and fresh embryos, Chinese medical journal 123(14): 1893-7.

Lidegaard, O., Pinborg, A. \& Andersen, A. (2005). Imprinting diseases and IVF: Danish National IVF cohort study, Human reproduction (Oxford, England) 20(4): 950-4.

Lie, R. T., Lyngstadaas, A., Ørstavik, K. H., Bakketeig, L. S., Jacobsen, G. \& Tanbo, T. (2005). Birth defects in children conceived by ICSI compared with children conceived by other IVF-methods; a meta-analysis., International journal of epidemiology 34(3): 696-701.

Liebaers, I., Desmyttere, S., Verpoest, W., De Rycke, M., Staessen, C., Sermon, K., Devroey, P., Haentjens, P. \& Bonduelle, M. (2010). Report on a consecutive series of 581 children born after blastomere biopsy for preimplantation genetic diagnosis., Human reproduction (Oxford, England) 25(1): 275-82.

Ludwig, A. K., Katalinic, A., Thyen, U., Sutcliffe, A. G., Diedrich, K. \& Ludwig, M. (2009). Physical health at 5.5 years of age of term-born singletons after intracytoplasmic sperm injection: results of a prospective, controlled, single-blinded study., Fertility and sterility 91(1): 115-24.

Ludwig, A., Katalinic, A., Entenmann, A., Thyen, U., Sutcliffe, A., Diedrich, K. \& Ludwig, M. (2009). Can we sense ART? The blinded examiner is not blind-a problem with follow-up studies on children born after assisted reproduction, Fertility and sterility 92(3): 950-952.

Maher, E. R., Brueton, L. A., Bowdin, S. C., Luharia, A., Cooper, W., Cole, T. R., Macdonald, F., Sampson, J. R., Barratt, C. L., Reik, W. \& Hawkins, M. M. (2003). Beckwith-Wiedemann syndrome and assisted reproduction technology (ART)., Journal of medical genetics 40(1): 62-4.

Mateu, E., Rodrigo, L., Martínez, M. C., Peinado, V., Milán, M., Gil-Salom, M., Martínez-Jabaloyas, J. M., Remohí, J., Pellicer, A. \& Rubio, C. (2010). Aneuploidies in embryos and spermatozoa from patients with $\mathrm{Y}$ chromosome microdeletions., Fertility and sterility 94(7): 2874-7.

MRC Working Party on Children Conceived by In Vitro Fertilisation (1990). Births in Great Britain resulting from assisted conception, 1978-87., BMJ (Clinical research ed.) 300(6734): 1229-33.

Odom, L. N. \& Segars, J. (2010). Imprinting disorders and assisted reproductive technology., Current opinion in endocrinology, diabetes, and obesity 17(6): 517-22.

Palermo, G., Joris, H., Devroey, P. \& Van Steirteghem, A. (1992). Pregnancies after intracytoplasmic injection of single spermatozoon into an oocyte, The Lancet 340(8810): 17-18. 
Reefhuis, J., Honein, M. A., Schieve, L. A., Correa, A., Hobbs, C. A., Rasmussen, S. A. \& National Birth Defects Prevention Study (2009). Assisted reproductive technology and major structural birth defects in the United States., Human reproduction (Oxford, England) 24(2): 360-6.

Rimm, A. A., Katayama, A. C., Diaz, M. \& Katayama, K. P. (2004). A meta-analysis of controlled studies comparing major malformation rates in IVF and ICSI infants with naturally conceived children., Journal of assisted reproduction and genetics 21(12): 437-43.

Rimm, A. A., Katayama, A. C. \& Katayama, K. P. (2011). A meta-analysis of the impact of IVF and ICSI on major malformations after adjusting for the effect of subfertility., Journal of assisted reproduction and genetics .

Rubio, C. (2010). Update on preimplantation genetic diagnosis for chromosomal abnormalities., Expert review of molecular diagnostics 10(8): 973-6.

Sato, A., Otsu, E., Negishi, H., Utsunomiya, T. \& Arima, T. (2007). Aberrant DNA methylation of imprinted loci in superovulated oocytes., Human reproduction (Oxford, England) 22(1): 26-35.

Schieve, L., Cohen, B., Nannini, A., Ferre, C., Reynolds, M., Zhang, Z., Jeng, G., Macaluso, M. \& Wright, V. (2007). A population-based study of maternal and perinatal outcomes associated with assisted reproductive technology in Massachusetts, Maternal and child health journal 11(6): 517-525.

Schieve, L., Meikle, S., Ferre, C., Peterson, H., Jeng, G. \& Wilcox, L. (2002). Low and very low birth weight in infants conceived with use of assisted reproductive technology, New England Journal of Medicine 346(10): 731-737.

Shuman, C., Smith, A. \& Weksberg, R. (2005). Beckwith-Wiedemann syndrome, GeneReviews at GeneTests: Medical Genetics Information Resource (database online). Seattle: University of Washington .

Simpson, J. L. (1996). Registration of congenital anomalies in ART populations: pitfalls., Human reproduction (Oxford, England) 11 Suppl 4: 81-8.

Spinner, N. B., Saitta, S. C., Delaney, D. P., Colliton, R., Zderic, S. A., Ruchelli, E., Zackai, E. \& Kolon, T. F. (2008). Intracytoplasmic sperm injection (ICSI) with transmission of a $\operatorname{ring}(\mathrm{Y})$ chromosome and ovotesticular disorder of sex development in offspring., American journal of medical genetics. Part A 146A(14): 1828-31.

Stark, Z., Storen, R., Bennetts, B., Savarirayan, R. \& Jamieson, R. V. (2011). Isolated hypogonadotropic hypogonadism with SOX2 mutation and anophthalmia/microphthalmia in offspring., European journal of human genetics : EJHG .

Strawn, E. Y., Bick, D. \& Swanson, A. (2010). Is it the patient or the IVF? Beckwith-Wiedemann syndrome in both spontaneous and assisted reproductive conceptions., Fertility and sterility 94(2): 754.e1-2.

Strömberg, B., Dahlquist, G., Ericson, A., Finnström, O., Köster, M. \& Stjernqvist, K. (2002). Neurological sequelae in children born after in-vitro fertilisation: a population-based study, Lancet 359(9305): 461-5.

Sutcliffe, A., D'souza, S., Cadman, J., Richards, B., McKinlay, I. \& Lieberman, B. (1995). Minor congenital anomalies, major congenital malformations and development in children conceived from cryopreserved embryos, Human Reproduction 10(12): 3332.

Tararbit, K., Houyel, L., Bonnet, D., De Vigan, C., Lelong, N., Goffinet, F. \& Khoshnood, B. (2011). Risk of congenital heart defects associated with assisted reproductive technologies: a population-based evaluation., European heart journal 32(4): 500-8. 
Tesarik, J. \& Mendoza, C. (1996). Genomic imprinting abnormalities: a new potential risk of assisted reproduction., Molecular human reproduction 2(5): 295-8.

Turan, N., Katari, S., Gerson, L., Chalian, R., Foster, M., Gaughan, J., Coutifaris, C. \& Sapienza, C. (2010). Inter- and intra-individual variation in allele-specific DNA methylation and gene expression in children conceived using assisted reproductive technology, PLoS genetics 6(7).

Vicdan, A., Vicdan, K., Günalp, S., Kence, A., Akarsu, C., Işik, A. Z. \& Sözen, E. (2004). Genetic aspects of human male infertility: the frequency of chromosomal abnormalities and $\mathrm{Y}$ chromosome microdeletions in severe male factor infertility., European journal of obstetrics, gynecology, and reproductive biology 117(1): 49-54.

Wen, S. W., Leader, A., White, R. R., Léveillé, M.-C., Wilkie, V., Zhou, J. \& Walker, M. C. (2010). A comprehensive assessment of outcomes in pregnancies conceived by in vitro fertilization/intracytoplasmic sperm injection., European journal of obstetrics, gynecology, and reproductive biology 150(2): 160-5.

Wennerholm, U., Söderström-Anttila, V., Bergh, C., Aittomäki, K., Hazekamp, J., Nygren, K., Selbing, A. \& Loft, A. (2009). Children born after cryopreservation of embryos or oocytes: a systematic review of outcome data, Human Reproduction 24(9): 2158.

Woldringh, G. H., Besselink, D. E., Tillema, A. H. J., Hendriks, J. C. M. \& Kremer, J. A. M. (2010). Karyotyping, congenital anomalies and follow-up of children after intracytoplasmic sperm injection with non-ejaculated sperm: a systematic review., Human reproduction update 16(1): 12-9.

Zhu, J., Hvidtjørn, D., Basso, O., Obel, C., Thorsen, P., Uldall, P. \& Olsen, J. (2010). Parental infertility and cerebral palsy in children, Human reproduction (Oxford, England) 25(12): 3142-5.

Zhu, J. L., Basso, O., Obel, C., Bille, C. \& Olsen, J. (2006). Infertility, infertility treatment, and congenital malformations: Danish national birth cohort., BMJ (Clinical research ed.) 333(7570): 679 . 


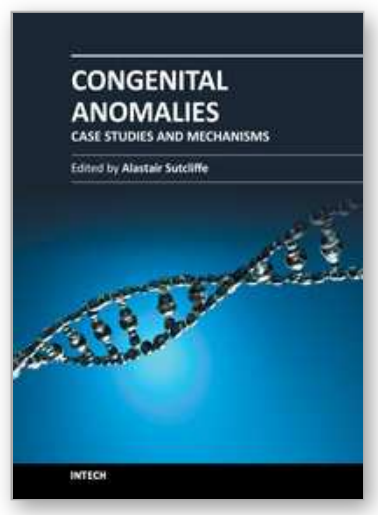

\author{
Congenital Anomalies - Case Studies and Mechanisms \\ Edited by Dr. Alastair Sutcliffe
}

ISBN 978-953-51-0075-1

Hard cover, 132 pages

Publisher InTech

Published online 22, February, 2012

Published in print edition February, 2012

This book is in essence a collection of essays which are state of the art in their respective areas of knowledge. They inform the reader of all sorts of mechanistic considerations when developing understanding of issues surrounding the origins of congenital abnormalities. These chapters are written by world renown authorities in this area of science and represent a wide range of expertise from a clinician perspective, through to genetic mechanisms. Unlike some books which take a formal textual, somewhat plodding way through pathophysiology here instead we have cut through chapters in which the student, or scientist or medic is lead to understand just how complex the origins can be via examples from different parts of the body. With the erudite chapters are relevant tables and other diagrams to help clarify the text. These chapters represent a starter text for the stimulus for further knowledge of what is an increasingly important area of human health.

\title{
How to reference
}

In order to correctly reference this scholarly work, feel free to copy and paste the following:

Johanna A. Reed and Alastair G. Sutcliffe (2012). Assisted Reproductive Technology and Congenital Malformations, Congenital Anomalies - Case Studies and Mechanisms, Dr. Alastair Sutcliffe (Ed.), ISBN: 978953-51-0075-1, InTech, Available from: http://www.intechopen.com/books/congenital-anomalies-case-studiesand-mechanisms/assisted-reproductive-technology-and-congenital-malformations

\section{INTECH}

open science | open minds

\author{
InTech Europe \\ University Campus STeP Ri \\ Slavka Krautzeka 83/A \\ 51000 Rijeka, Croatia \\ Phone: +385 (51) 770447 \\ Fax: +385 (51) 686166 \\ www.intechopen.com
}

\author{
InTech China \\ Unit 405, Office Block, Hotel Equatorial Shanghai \\ No.65, Yan An Road (West), Shanghai, 200040, China \\ 中国上海市延安西路65号上海国际贵都大饭店办公楼 405 单元 \\ Phone: +86-21-62489820 \\ Fax: +86-21-62489821
}


(C) 2012 The Author(s). Licensee IntechOpen. This is an open access article distributed under the terms of the Creative Commons Attribution 3.0 License, which permits unrestricted use, distribution, and reproduction in any medium, provided the original work is properly cited. 